\title{
Identification of bioactive heterocyclic compounds from mulberry and their protective effect against streptozotocin-induced apoptosis in INS-1 cells
}

\author{
JI HOON SONG ${ }^{1 *}$, DAHAE LEE ${ }^{2,3 *}$, SEOUNG RAK LEE ${ }^{3}$, JAE SIK YU ${ }^{3}$, \\ TAE SU JANG ${ }^{4}$, JOO-WON NAM ${ }^{5}$, KI HYUN KIM ${ }^{3}$ and KI SUNG KANG ${ }^{2}$
}

\author{
${ }^{1}$ Department of Medicine, University of Ulsan College of Medicine, Seoul 05505; ${ }^{2}$ College of Korean Medicine, \\ Gacheon University, Seongnam, Gyeonggi 13120; ${ }^{3}$ School of Pharmacy, Sungkyunkwan University, Suwon, Gyeonggi 16419; \\ ${ }^{4}$ Institute of Green Bio Science and Technology, Seoul National University, Pyeongchang, \\ Gangwon 25354; ${ }^{5}$ College of Pharmacy, Yeungnam University, Gyeongsan, Gyeongbuk 38541, Republic of Korea
}

Received September 6, 2017; Accepted January 15, 2018

DOI: $10.3892 / \mathrm{mmr} .2018 .8582$

\begin{abstract}
A phytochemical investigation of the $\mathrm{MeOH}$ extracts from mulberries (the fruit of Morus alba L.) led to the identification of six heterocyclic compounds (1-6). These compounds were screened to detect whether they protected pancreatic INS-1 cells from streptozotocin (STZ)-induced cytotoxicity. Compound 3 was the most effective at preventing STZ-induced cytotoxicity and the production of reactive oxygen species (ROS) in INS-1 cells. In addition, compound 3 effectively prevented apoptosis induced by STZ in INS-1 cells. Compound 3 also prevented STZ-mediated cleavage of caspase-8, caspase-3 and poly (ADP-ribose) polymerase and increased the expression of B-cell lymphoma-2 (Bcl-2), an anti-apoptotic Bcl-2 family protein. In conclusion, the results of the present study indicate that compound 3 extracted from the fruit of $M$. alba was highly effective in preventing type 1 diabetes mellitus and may be a novel treatment option.
\end{abstract}

\section{Introduction}

Diabetes mellitus, mainly caused by various genetic and environmental factors, is a chronic and systemic metabolic

Correspondence to: Professor Ki Sung Kang, College of Korean Medicine, Gacheon University, 1342 Seongnam-daero, Seongnam, Gyeonggi 13120, Republic of Korea

E-mail:kkang@gachon.ac.kr

Professor Ki Hyun Kim, School of Pharmacy, Sungkyunkwan University, 2066 Seobu-ro, Suwon, Gyeonggi 16419, Republic of Korea

E-mail:khkim83@skku.edu

${ }^{*}$ Contributed equally

Key words: Morus alba, streptozotocin, type 1 diabetes mellitus, reactive oxygen species syndrome. Diabetes results from a shortage in the amount of insulin released from the pancreas in response to elevated blood glucose or from a deficiency in the ability of fat and muscle cells to respond to insulin (1). The representative symptoms of diabetes are increased hunger, frequent urination, and increased thirst, and untreated diabetes causes a variety of complications including chronic kidney disease, stroke, cardiovascular disease, and diabetic retinopathy (1-3). Type 1 diabetes, also called insulin-dependent diabetes mellitus (IDDM), occurs via an autoimmune reaction that attacks the $\beta$ cells of the pancreas that produce insulin (4). Type 2 diabetes, or non-insulin-dependent diabetes (NIDDM), is caused by a deficiency in the insulin-responsive system, and a strong connection between type 2 diabetes and obesity has become clear (5). Currently, there are many different classes of anti-diabetic drugs used in clinical practice to decrease blood glucose levels, such as metformin, glucagon-like peptide-1 receptor (GLP-1) agonists, and synthetic insulin analogs $(2,6)$. Nevertheless, many studies on natural products are being carried out to discover potent anti-diabetic lead compounds that have minimal side effects.

Morus alba L. (Moraceae), known as the white mulberry tree, is cultivated in Asia, Europe, and India, and its fruits, commonly known as mulberry, are widely cultivated as an edible fruit (7). Mulberry has been used as a traditional medicine in East Asia for the prevention of insomnia, dizziness, and tinnitus as well as the alleviation of high glucose levels $(8,9)$. Previous researches have reported that various chemical constituents and extracts from this natural source exhibit useful pharmacological activities including anti-inflammatory, antioxidant, and immunoregulative effects (10-12). A recent study reported that anthocyanin-rich mulberry extracts alleviate high glucose levels in in vivo studies of glucose consumption and uptake, which was attributed to AMPK/ACC/mTOR signaling (13). In addition, anti-hyperglycemic and anti-hyperlipidemic effects of polysaccharides from the fruits of M. alba have been reported, which provide a scientific rationale for the development of this source as a new medication candidate to treat diabetes (14). However, anti-diabetic compounds/metabolites from M. alba 
fruits have not yet been fully investigated. The present study describes the protective effects of compounds isolated from M. alba fruits against STZ-induced INS-1 cell death as well as its molecular mechanisms in the apoptotic pathway.

\section{Materials and methods}

Extraction of M. alba fruits and isolation method. The fruits of M. alba were bought at the Kyungdong Market (Woori Herb), Seoul, Korea, in January, 2014. A voucher specimen (MA 1414) of the material was classified by one of the authors (K.H. Kim) and was stored in the herbarium of the School of Pharmacy, Sungkyunkwan University (Suwon, Korea). Dried and pounded fruits of $M$. alba $(10.0 \mathrm{~kg})$ were extracted with $70 \%$ aqueous $\mathrm{MeOH}$ three times at room temperature and then filtered. The filtrate was condensed in vacuo, affording a slurry resultant $(1.4 \mathrm{~kg})$. The resultant residue was dissolved in deionized water and successively partitioned with hexane, $\mathrm{CHCl}_{3}, \mathrm{EtOAc}$, and $n-\mathrm{BuOH}(800 \mathrm{ml} \times 3)$ until the color of partitioned layer disappears, providing 27.8, 85.3, 32.9, and $138.8 \mathrm{~g}$, respectively. The $\mathrm{CHCl}_{3}$-soluble fraction $(85.0 \mathrm{~g}$ ) was loaded to a silica gel (230-400 mesh) column and fractionated using $\mathrm{CHCl}_{3}-\mathrm{MeOH}$ (40:1-1:1, gradient system) to yield five fractions (CA-CE). Fraction CB (4.3 g) was separated by RP-C 18 silica gel (230-400 mesh) column chromatography eluted with $70 \% \mathrm{MeOH} / \mathrm{H}_{2} \mathrm{O}$ to give eleven fractions (CB1-CB11). Fraction CB1 (226 mg) was passed over Sephadex LH-20 column chromatography eluted with $100 \% \mathrm{MeOH}$ to give six subfractions (CB1-1-CB1-6). Subfraction CB1-3 (33 mg) was purified by semi-preparative reversed-phase HPLC using an isocratic solvent system of $4 \% \mathrm{MeOH} / \mathrm{H}_{2} \mathrm{O}$ (Phenomenex Luna Phenyl-hexyl, 250x10.0 mm, $5 \mu \mathrm{m}$, flow rate: $2 \mathrm{ml} / \mathrm{min}$ ) to afford compounds $1\left(0.4 \mathrm{mg}, t_{\mathrm{R}}=25.0 \mathrm{~min}\right)$ and $2(4.4 \mathrm{mg}$, $\left.t_{\mathrm{R}}=37.2 \mathrm{~min}\right)$. Fraction CB2 (750 mg) was fractionated using silica gel (230-400 mesh) column chromatography eluted with $\mathrm{CHCl}_{3}-\mathrm{MeOH}$ (40:1-5:1, gradient system) to afford nine subfractions (CB2-1-CB2-9). Subfraction CB2-2 (176 mg) was purified by semi-preparative reversed-phase HPLC using an isocratic solvent system of $29 \% \mathrm{MeOH} / \mathrm{H}_{2} \mathrm{O}$ (Phenomenex Luna Phenyl-hexyl, 250x10.0 mm, $5 \mu \mathrm{m}$, flow rate: $2 \mathrm{ml} / \mathrm{min}$ ) to yield compounds $3\left(2.1 \mathrm{mg}, t_{\mathrm{R}}=72.0 \mathrm{~min}\right)$ and $4(1.6 \mathrm{mg}$, $\left.t_{\mathrm{R}}=65.1 \mathrm{~min}\right)$. Subfraction CB2-3 (84 mg) was also separated by semi-preparative reversed-phase HPLC using an isocratic solvent system of $18 \% \mathrm{MeOH} / \mathrm{H}_{2} \mathrm{O}$ (Phenomenex Luna Phenyl-hexyl, 250x10.0 mm, $5 \mu \mathrm{m}$, flow rate: $2 \mathrm{ml} / \mathrm{min}$ ) to afford compound $5\left(1.3 \mathrm{mg}, t_{\mathrm{R}}=40.5 \mathrm{~min}\right)$. Finally, fraction CB4 was separated on silica gel (230-400 mesh) column chromatography using $\mathrm{CHCl}_{3}-\mathrm{MeOH}$ (40:1-5:1, gradient system) to give seven subfractions (CB4-1-CB4-7). Compound $6\left(1.8 \mathrm{mg}, t_{\mathrm{R}}=26.1 \mathrm{~min}\right)$ was purified from subfraction $\mathrm{CB} 4-2$ (20.0 mg) by utilizing semi-preparative reversed-phase HPLC with an isocratic solvent system of $58 \% \mathrm{MeOH} / \mathrm{H}_{2} \mathrm{O}$ (Phenomenex Luna Phenyl-hexyl, 250x10.0 mm, $5 \mu \mathrm{m}$, flow rate: $2 \mathrm{ml} / \mathrm{min}$ ).

Cell culture. INS-1 cell line, immortalized rat pancreatic islet beta cells, were purchased from Biohermes (Shanghai, China) and grown in RPMI-1640 (Cellgro, Manassas, VA, USA) supplemented with $10 \% \mathrm{FBS}, 1 \%$ penicillin/streptomycin (Invitrogen Co., Grand Island, NY, USA), $11 \mathrm{mM}$ d-glucose,

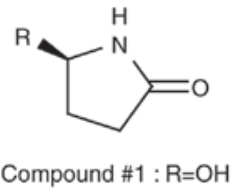

Compound \#2: $\mathrm{R}=\mathrm{CO}_{2} \mathrm{CH}_{3}$

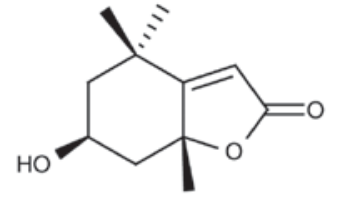

Compound \#3

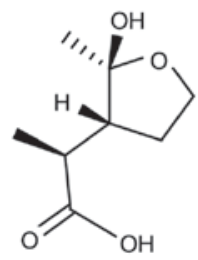

Compound \#5<smiles>O=Cc1coc2ccccc12</smiles>

Compound \#4<smiles>c1ccc2[nH]ccc2c1</smiles>

Compound \#6
Figure 1. The chemical structures of the compounds (1-6).

$10 \mathrm{mM}$ HEPES, $2 \mathrm{mM}$ l-glutamine, $1 \mathrm{mM}$ sodium pyruvate, and $0.05 \mathrm{mM}$ 2-mercaptoethanol in an humidified atmosphere supplying of $5 \% \mathrm{CO}_{2}$ at $37^{\circ} \mathrm{C}$.

Measurement of the level of intracellular ROS. The levels of intracellular ROS were measured using 2',7'-dichlorodihydrofluorescein diacetate $\left(\mathrm{H}_{2} \mathrm{DCF}-\mathrm{DA}\right.$; Sigma, St Louis, MO, USA). Cells were plated into clear bottomed 96-well black plates at a density of $2 \times 10^{4}$ cells per well and adhered for $24 \mathrm{~h}$. After the pre-treatment with control or indicated concentrations of compounds for $2 \mathrm{~h}$, cells were then exposed to $50 \mu \mathrm{M}$ streptozotocin (STZ; Sigma) for additional $24 \mathrm{~h}$. After incubation, cells were stained $10 \mathrm{uM} \mathrm{H}_{2}$ DCFDA for $30 \mathrm{~min}$ followed by washing with PBS three times. Green DCF fluorescent intensity was measured at an excitation wavelength of $485 \mathrm{~nm}$ and an emission wavelength of $535 \mathrm{~nm}$ (Ex/Em) using a fluorescent microplate reader (Tecan Infinite F200 Microplate Fluorescence Reader; Tecan Zürich, Switzerland).

Assessment of cell viability. Cell viability were determined using Ez-Cytox cell viability detection kit following manufacturer's instruction. In brief, cells were grown in 96-well plate at a density of $2 \times 10^{4}$ cells per well for $24 \mathrm{~h}$. Cells were then pre-treated with control $(0.5 \%$ DMSO) or the indicated concentrations of compounds. After incubation for $2 \mathrm{~h}$, cells were exposed to $50 \mu \mathrm{M}$ STZ for $24 \mathrm{~h}$. Cells were then incubated with $10 \mu \mathrm{l}$ Ez-Cytox for additional $2 \mathrm{~h}$. Cell viability was determined from the absorbance at $450 \mathrm{~nm}$ using a microplate reader.

Tali-image based analysis of apoptotic cells. Cells were plated in 6-well plates at a density of $3 \times 10^{5}$ cells per well and incubated for $24 \mathrm{~h}$ to adhere. Cells were pre-treated with 50 and $100 \mu \mathrm{M}$ compound 3 for $2 \mathrm{~h}$ and exposed to $50 \mu \mathrm{M} \mathrm{STZ}$ for $24 \mathrm{~h}$. The cells were then harvested and washed with PBS. 

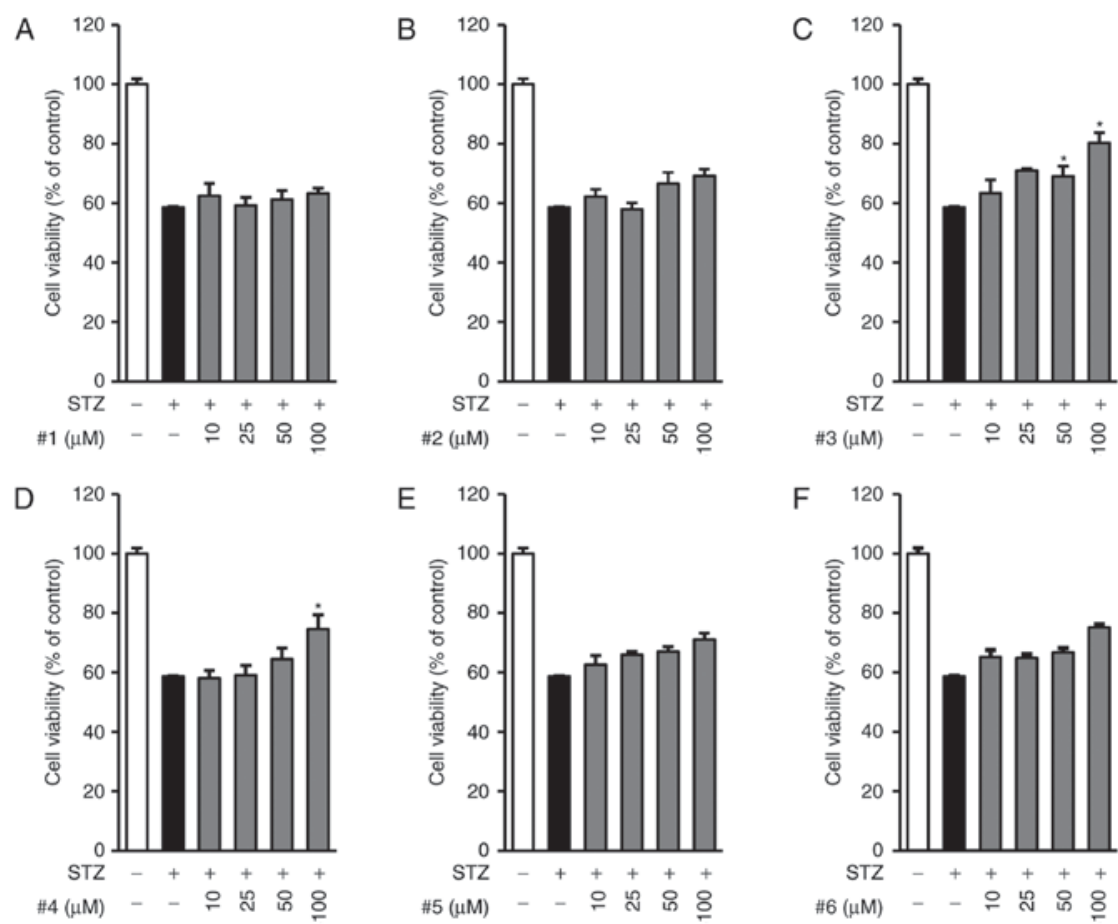

Figure 2. The protective effects of the compounds 1-6 against STZ-induced cytotoxicity in INS-1 cells. INS-1 cells were exposed to $50 \mu \mathrm{M}$ STZ for $24 \mathrm{~h}$ in the presence of compounds (A) 1, (B) 2, (C) 3, (D) 4, (E) 5 and (F) 6 (0-100 $\mu \mathrm{M})$, and cell viability was determined. The presence of compound 3 showed a strong protective effect against STZ-induced INS-1 cytotoxicity. Mean \pm SEM, ${ }^{*} \mathrm{P}<0.05$ compared with STZ only treated cells. STZ, streptozotocin.

Cells were incubated with an Annexin V Alexa Fluor 488 in Annexin-binding buffer for 20 min followed by staining with propidium iodide (PI). The percentage of apoptotic cells was analyzed using a Tali image-based cytometer (Invitrogen, CA, USA). In this analysis, the apoptotic cells were determined by the percentage of Annexin V-positive cells on total counted-cells.

Western blot analysis. Cells were plated in 6-well plates at a density of $3 \times 10^{5}$ cells per well and incubated for $24 \mathrm{~h}$ to adhere. Cells were pre-treated with 50 and $100 \mu \mathrm{M}$ compound 3 for $2 \mathrm{~h}$ and exposed to $50 \mu \mathrm{M} \mathrm{STZ}$ for $24 \mathrm{~h}$. Cells were then lysed with RIPA buffer supplemented with $1 \mathrm{mM}$ phenylmethylsulfonyl fluoride immediately before use. The equal amounts of protein were separated by a sodium dodecyl sulfate-polyacrylamide gel electrophoresis and transferred onto polyvinylidene difluoride membranes. The membranes were incubated with primary antibodies against cleaved caspase-8, cleaved caspase- 9 , cleaved caspase-3, B-cell lymphoma-2 (BCL-2), PARP, and glyceraldehyde 3-phosphate dehydrogenase (GAPDH). The membranes were then incubated with horseradish peroxidase (HRP)-conjugated secondary antibodies. Immunoreactive bands were detected using ECL Advance western blotting detection reagents (GE Healthcare, Chalfont, UK) and visualized using a FUSION Solo Chemiluminescence System (PEQLAB Biotechnologie GmbH, Germany).

Statistical analysis. Differences between treatments were evaluated by one-way analysis of variance (ANOVA) followed by a multiple comparison test with a Bonferroni adjustment. $\mathrm{P}<0.05$ was considered to indicate a statistically significant difference.

\section{Results and Discussion}

The $\mathrm{MeOH}$ extract of $M$. alba fruits was partitioned with hexane, $\mathrm{CHCl}_{3}$, EtOAc, and $n-\mathrm{BuOH}$. The $\mathrm{CHCl}_{3}$-soluble fraction was subjected to a series of open-column chromatography and Sephadex-LH20 column chromatography, and then purified by semi-preparative HPLC, to obtain six heterocyclic compounds (1-6) (Fig. 1). The chemical structures of the isolated compounds were unambiguously elucidated to be (R)-5-hydroxypyrrolidin-2-one (1,15), methyl (R)-pyroglutamate $(2,16)$, loliolide $(3,17), 3$-benzofurancarboxaldehyde $(4,18)$, odisolane $(5,19)$, and indole $(6,20)$ by comparing their NMR spectroscopic values and physical properties with previously reported literature data.

We first examined the effects of all compounds on the cell viability decreased by STZ in INS-1 cells. Cells were pre-treated with the indicated concentrations of compounds 1-6 ( 0 to $100 \mu \mathrm{M}$ of each compound) for $2 \mathrm{~h}$ and further exposed to $50 \mu \mathrm{M}$ STZ for $24 \mathrm{~h}$. As shown in Fig. 2, the exposure to $50 \mu \mathrm{M}$ STZ for $24 \mathrm{~h}$ decreased cell viability $(58.62 \pm 0.17 \%)$ compared to control treatment (100\%). Among the six compounds, compound 3 showed the strongest protective effect on STZ-induced INS-1 cytotoxicity in a concentration-dependent manner, whereas the other compounds showed minimal or no effect (Fig 2A-F). Compound 3 showed maximum effect at the concentration of $100 \mu \mathrm{M}$, as indicated by increased cell viability $(80.27 \pm 3.48 \%)$.

The increase in the levels of intracellular ROS is a key characteristic in STZ-induced pancreatic $\beta$-cell death (21). Therefore, we then examined the antioxidative effects of compounds 1-6. Consistent with previous studies, we found, as shown in Fig. 3, a remarkable increase in intracellular ROS after 
A

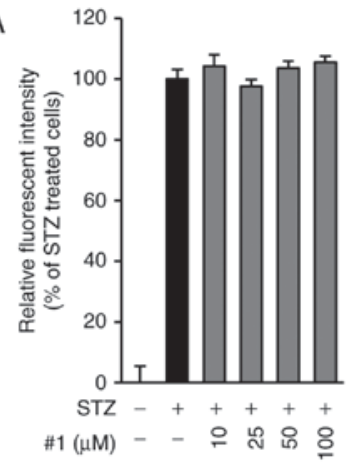

D

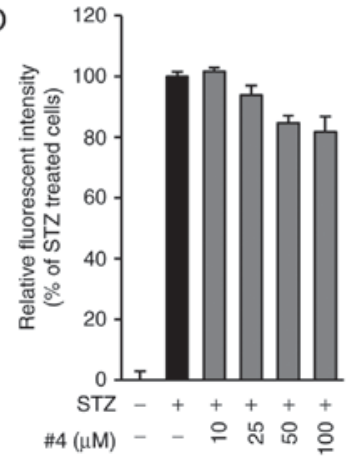

B

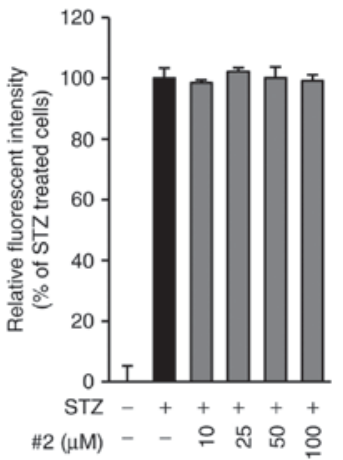

E

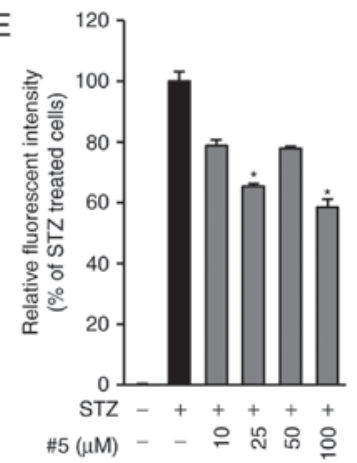

C

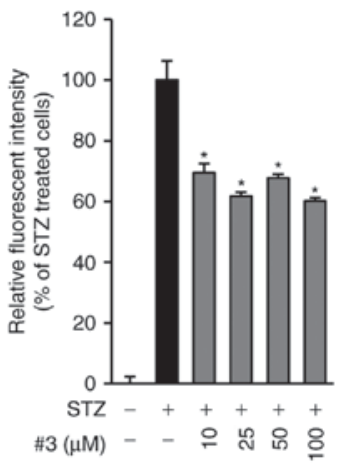

$\mathrm{F}$

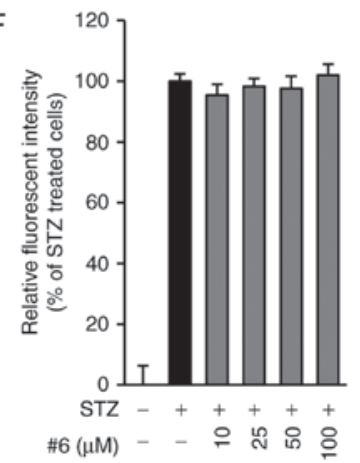

Figure 3. Scavenging activities of compounds 1-6 against STZ-induced ROS production. INS-1 cells were exposed to $50 \mu \mathrm{M} \mathrm{STZ}$ for $24 \mathrm{~h}$ in the presence of compounds (A) 1, (B) 2, (C) 3, (D) 4, (E) 5 and (F) 6 (0-100 $\mu \mathrm{M}$ ) and stained with $\mathrm{H}_{2}$ DCFDA. Fluorescent intensities of DCF were measured using a fluorescent microplate reader. The presence of compound 3 showed a strong protective effect on STZ-induced INS-1 cells. Mean \pm SEM, ${ }^{*} \mathrm{P}<0.05$ compared with STZ only treated cells. STZ, streptozotocin; ROS, reactive oxygen species; $\mathrm{H}_{2}$ DCFDA, 2',7'-dichlorodihydrofluorescein diacetate; DCF, dichlorofluorescein.

A

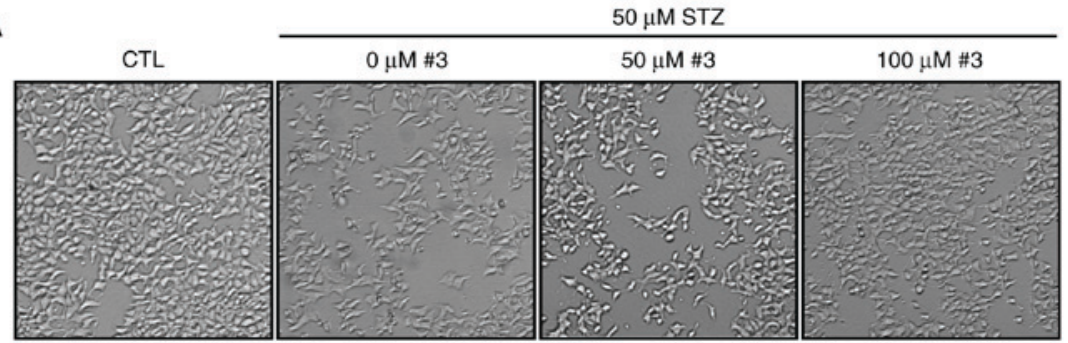

B

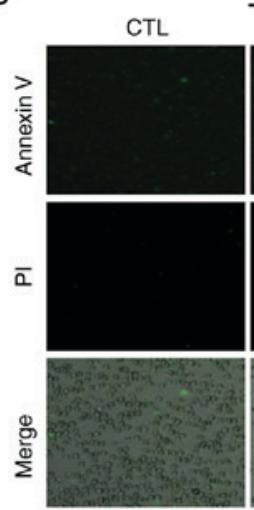

$50 \mu \mathrm{M} \mathrm{STZ}$

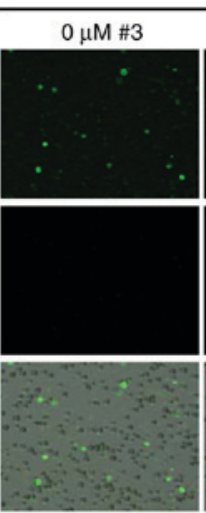

$50 \mu \mathrm{M} \# 3$

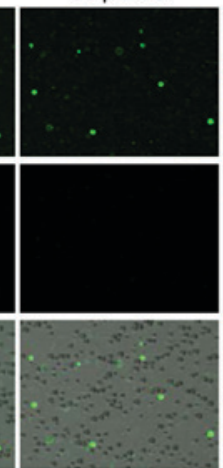

$100 \mu \mathrm{M} \# 3$

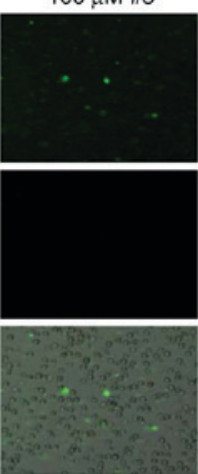

C

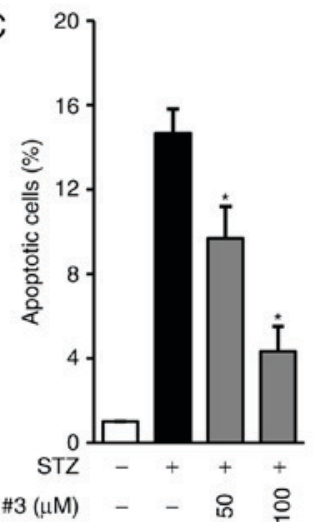

Figure 4 . The effect of compound 3 against STZ-induced apoptosis in INS-1 cells. Cells were pretreated with 50 and $100 \mu \mathrm{M}$ compound 3 for $2 \mathrm{~h}$ and then exposed to $50 \mu \mathrm{M} \mathrm{STZ}$. (A) Microscopic images show that treatment with compound 3 prevented cell death induced by STZ treatment. (B) Fluorescent images indicate that treatment with compound 3 reduced the increase in Annexin V-positive cells induced by STZ. (C) Bars denote the percentage of apoptotic cells. The percentage of apoptotic cells was significantly reduced by treatment with compound 3. Mean \pm SEM, $\mathrm{P}<0.05$ compared with STZ only treated cells. STZ, streptozotocin.

exposure to STZ for $24 \mathrm{~h}$. In contrast, compounds 3 (Fig. 3C) and 5 (Fig. 3E) significantly reduced the levels of intracellular
ROS that were increased by STZ in INS-cells, whereas the other compounds were not effective (Fig. 3A, B, D, F). Based 


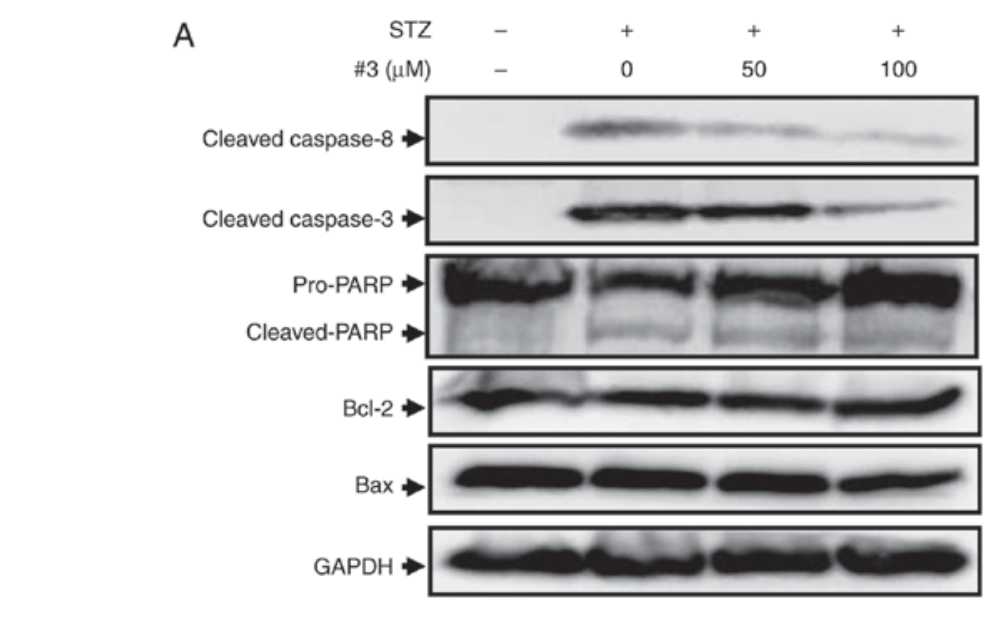

B

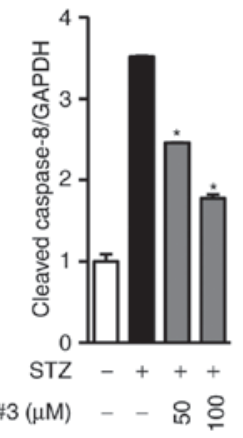

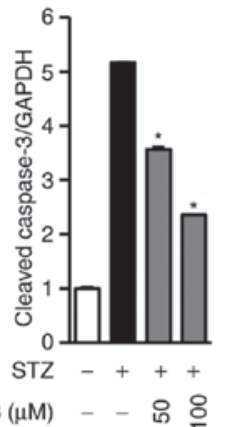

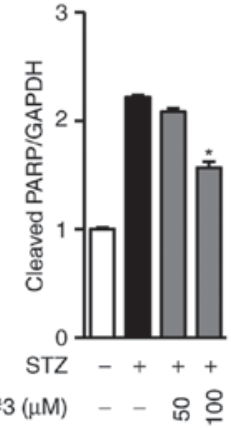

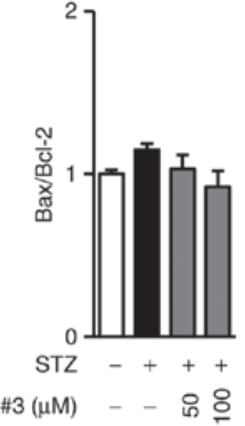

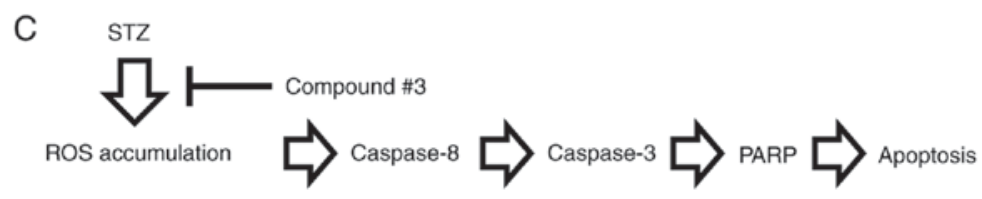

Figure 5. Underlying protective mechanism of compound 3 against STZ-induced apoptotic cell death. (A) Cells were exposed to $50 \mu \mathrm{M} \mathrm{STZ} \mathrm{for} 24 \mathrm{~h}$ after pretreatment with 50 and $100 \mu \mathrm{M}$ of compound 3 for $2 \mathrm{~h}$. (B) The graph represents the fold increase in cleaved caspase-8, cleaved caspase-9, and PARP. GAPDH was used as a loading control. Treatment with compound 3 decreased the cleavage of caspase- 8 , caspase-3, and PARP and increased Bcl-2 protein expression. (C) The mechanism of protection mediated by compound 3 against STZ-induced INS-1 cell death. "P $<0.05$ compared with STZ only treated cells. STZ, streptozotocin; ROS, reactive oxygen species; GAPDH, glyceraldehyde 3-phosphate dehydrogenase; PARP, poly (ADP-ribose) polymerase; Bcl-2, B-cell lymphoma 2.

on the results of both the cell viability assay and the ROS measurement studies, we found that compound 3 was the most effective in preventing INS-1 cell death and the production of ROS induced by STZ. Therefore, we further investigated not only the anti-apoptotic effect of compound 3 but also its underlying mechanism against STZ-induced apoptotic cell death.

It has been reported that STZ induces apoptosis and necrosis at low and high concentrations respectively and that both apoptosis and necrosis contribute to the development of type 1 diabetes $(22,23)$. Therefore, we examined the effect of compound 3 against STZ-induced apoptosis in INS-1 cells. The morphological images in Fig. 4A show that the presence of compound 3 strongly prevented STZ-induced apoptosis in INS-1 cells (Fig. 4A). To determine the anti-apoptotic effect, cells were stained with Annexin-V Allexa 488 after exposure to $50 \mu \mathrm{M} \mathrm{STZ}$ in the presence of 50 and $100 \mu \mathrm{M}$ compound 3 . The representative photographs show that the treatment with compound 3 markedly reduced the Annexin V-positive cells (Fig. 4B). In addition to this, we quantitatively analyzed apoptotic cells by the percentage of Annexin V-positive cells relative to total cells. As shown in Fig. 4C, the percentage of apoptotic cells dramatically increased by the exposure to STZ $(14.66 \pm 1.15 \%)$ while it was significantly reduced in the presence of $50(9.66 \pm 1.52 \%)$ and $100 \mu \mathrm{M}(4.33 \pm 1.15 \%)$ compound 3 (Fig. 4C).

STZ induces apoptosis via activation of caspase- 8 and caspase-3 and regulation of the protein expression of $\mathrm{Bcl}-2$ family members in INS-1 cells (24). Moreover, we recently reported that the inhibition of caspase- 8 and caspase- 3 by cirsimaritin prevented apoptosis in INS-1 cells as well as increased Bcl-2 protein expression (25). This suggests that the inhibition of the caspase signaling pathway is a possible target to protect pancreatic cell death in type 1 diabetes. We further investigated to determine the underlying protective mechanism of compound 3 against STZ-induced apoptotic INS-1 cell death using western blot analysis for pro-apoptotic and anti-apoptotic proteins. As shown in Fig. 5A, cleavage of caspase-8, caspase-3, and PARP was markedly increased after treatment with $50 \mu \mathrm{M} \mathrm{STZ}$, whereas it decreased in the presence of 50 and $100 \mu \mathrm{M}$ of compound 3 in a concentration-dependent manner (Fig. 5B). However, the ratio of Bax to Bcl-2 indicating 
mitochondrial apoptotic pathway was altered neither cisplatin only-nor cisplatin with compound 3-treated cells (Fig 5A and $\mathrm{B})$. This result indicated that compound 3 exhibits anti-apoptotic activity via blocking the activation of caspase- 8 and caspase-3 and inducing PARP cleavage (Fig. 5C).

In the present study, we found that compound 3 prevented STZ-induced apoptotic pancreatic $\beta$ cell death via the inhibition of the caspase signaling pathway and induction of Bcl-2 protein expression. Therefore, this study suggests that compound 3, a strong bioactive natural compound from the extracts of $M$. alba, may be a suitable therapeutic for type 1 diabetes.

\section{Acknowledgements}

The present study was supported by the Basic Science Research Program through the National Research Foundation of Korea (NRF) funded by the Ministry of Science, ICT, and Future Planning (NRF-2017R1A2B2011807). The present study was also supported by the Basic Science Research Program through the National Research Foundation of Korea (NRF) funded by the Ministry of Science, ICT, and Future Planning (2015R1C1A1A02037383).

\section{References}

1. Pantalone KM, Hobbs TM, Wells BJ, Kong SX, Kattan MW, Bouchard J, Yu C, Sakurada B, Milinovich A, Weng W, et al: Clinical characteristics, complications, comorbidities and treatment patterns among patients with type 2 diabetes mellitus in a large integrated health system. BMJ Open Diabetes Res Care 3: e000093, 2015

2. Constantino MI, Molyneaux L, Limacher-Gisler F, Al-Saeed A, Luo C, Wu T, Twigg SM, Yue DK and Wong J: Long-term complications and mortality in young-onset diabetes: Type 2 diabetes is more hazardous and lethal than type 1 diabetes. Diabetes Care 36: 3863-3869, 2013.

3. Emerging Risk Factors Collaboration, Sarwar N, Gao P, Seshasai SR, Gobin R, Kaptoge S, Di Angelantonio E, Ingelsson E, Lawlor DA, Selvin E, et al: Diabetes mellitus, fasting blood glucose concentration, and risk of vascular disease: A collaborative meta-analysis of 102 prospective studies. Lancet 375: 2215-2222, 2010.

4. Rother KI: Diabetes treatment-bridging the divide. N Engl J Med 356: 1499-1501, 2007.

5. Malik VS, Popkin BM, Bray GA, Després JP and Hu FB: Sugar-sweetened beverages, obesity, type 2 diabetes mellitus, and cardiovascular disease risk. Circulation 121: 1356-1364, 2010.

6. Ripsin CM, Kang H and Urban RJ: Management of blood glucose in type 2 diabetes mellitus. Am Fam Physician 79: 29-36, 2009.

7. Khan MA, Rahman AA, Islam S, Khandokhar P, Parvin S, Islam MB, Hossain M, Rashid M, Sadik G, Nasrin S, et al: A comparative study on the antioxidant activity of methanolic extracts from different parts of Morus alba L. (Moraceae). BMC Res Notes 6: 24, 2013

8. Oki T, Kobayashi M, Nakamura T, Okuyama A, Masuda M, Shiratsuchi $\mathrm{H}$ and Suda I: Changes in radical-scavenging activity and components of mulberry fruit during maturation. J Food Sci 71: C18-C22, 2006.
9. Pawlowska AM, Oleszek W and Braca A: Quali-quantitative analyses of Flavonoids of Morus nigra L. and Morus alba L. (Moraceae) fruits. J Agric Food Chem 56: 3377-3380, 2008.

10. Guo C,LiR,Zheng N,Xu L,Liang T and He Q: Anti-diabetic effect of ramulus mori polysaccharides, isolated from Morus alba L., on STZ-diabetic mice through blocking inflammatory response and attenuating oxidative stress. Int Immunopharmacol 16: 93-99, 2013.

11. Ren C, Zhang Y, Cui W, Lu G, Wang Y, Gao H, Huang L and Mu Z: A polysaccharide extract of mulberry leaf ameliorates hepatic glucose metabolism and insulin signaling in rats with type 2 diabetes induced by high fat-diet and streptozotocin. Int J Biol Macromol 72: 951-959, 2015.

12. Zelová H, Hanáková Z, Čermáková Z, Šmejkal K, Dalí Acqua S, Babula P, Cvačka J and Hošek J: Evaluation of anti-inflammatory activity of prenylated substances isolated from Morus alba and Morus nigra. J Nat Prod 77: 1297-1303, 2014.

13. Yan $\mathrm{F}$ and Zheng $\mathrm{X}$ : Anthocyanin-rich mulberry fruit improves insulin resistance and protects hepatocytes against oxidative stress during hyperglycemia by regulating AMPK/ACC/mTOR pathway. J Funct Foods 30: 270-281, 2017.

14. Jiao $Y$, Wang $X$, Jiang $X$, Kong $F$, Wang S and Yan C: Antidiabetic effects of Morus alba fruit polysaccharides on high-fat diet- and streptozotocin-induced type 2 diabetes in rats. J Ethnopharmacol 199: 119-127, 2017.

15. Kim KH, Lee IK, Park KM, Kim WK and Lee KR: Isolation of $\gamma$-Lactam Alkaloids from the Macrolepiota neomastoidea. Bullet Korean Che Soc 29: pp1591-1593, 2008.

16. Bateman L, Breeden SW and O'Leary P: New chiral diamide ligands: Synthesis and application in allylic alkylation. Tetrahedron: Asymmet 19: 391-396, 2008.

17. Kim MR, Lee SK, Kim CS, Kim KS and Moon DC: Phytochemical constituents ofCarpesium macrocephalum FR- et SAV. Arch Pharm Res 27: 1029-1033, 2004.

18. Podea PV, Toşa MI, Paizs C and Irimie FD: Chemoenzymatic preparation of enantiopure L-benzofuranyl- and L-benzo[b] thiophenyl alanines. Tetrahedron: Asymmet 19: 500-511, 2008.

19. Lee SR, Park JY, Yu JS, Lee SO, Ryu JY, Choi SZ, Kang KS, Yamabe $\mathrm{N}$ and Kim KH: Odisolane, a novel oxolane derivative, and antiangiogenic constituents from the fruits of mulberry (Morus alba L.). J Agric Food Chem 64: 3804-3809, 2016.

20. Siu J, Baxendale IR and Ley SV: Microwave assisted Leimgruber-Batcho reaction for the preparation of indoles, azaindoles and pyrroylquinolines. Org Biomol Chem 2: 160-167, 2004.

21. Chen F, Xiong H, Wang J, Ding X, Shu G and Mei Z: Antidiabetic effect of total flavonoids from Sanguis draxonis in type 2 diabetic rats. J Ethnopharmacol 149: 729-736, 2013.

22. Mythili MD, Vyas R, Akila G and Gunasekaran S: Effect of streptozotocin on the ultrastructure of rat pancreatic islets. Microsc Res Tech 63: 274-281, 2004.

23. Saini KS, Thompson C, Winterford CM, Walker NI and Cameron DP: Streptozotocin at low doses induces apoptosis and at high doses causes necrosis in a murine pancreatic beta cell line, INS-1. Biochem Mol Biol Int 39: 1229-1236, 1996.

24. Kasono K, Yasu T, Kakehashi A, Kinoshita N, Tamemoto H, Namai K, Ohno R, Ueba H, Kuroki M, Ishikawa S and Kawakami M: Nicorandil improves diabetes and rat islet beta-cell damage induced by streptozotocin in vivo and in vitro. Eur J Endocrinol 151: 277-285, 2004.

25. Lee D, Kim KH, Lee J, Hwang GS, Lee HL, Hahm DH, Huh CK, Lee SC, Lee S and Kang KS: Protective effect of cirsimaritin against streptozotocin-induced apoptosis in pancreatic beta cells J Pharm Pharmacol 69: 875-883, 2017. 